\title{
Clinical profile of 103 patients with abdominal tuberculosis in Nepal
}

\author{
Umid Kumar Shrestha ${ }^{1 *}$, Dinesh Shrestha², Ramila Shrestha ${ }^{2}$, Arnab Ghosh ${ }^{1}$
}

${ }^{1}$ Manipal College of Medical Sciences, Pokhara, Nepal, ${ }^{2}$ Bir Hospital, National Academy of Medical Sciences, Kathmandu, Nepal

\section{DOI Name}

http://dx.doi.org/10.3126/jaim.v4i2.16896

\section{Keywords}

Abdominal tuberculosis, clinical profile,

extrapulmonary tuberculosis, anti-tubercular treatment, therapeutic trial

\section{Citation}

Umid Kumar Shrestha, Dinesh Shrestha, Ramila Shrestha, Arnab Ghosh. Clincal profile of 103 patients with abdominal tuberculosis in Nepal. Journal of Advances in Internal Medicine 2015;04(02):51-56.

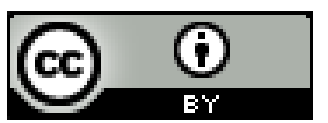

This work is licensed under a Creative Commons Attribution 3.0 Unported License.

\begin{abstract}
Background and aims: The nonspecific clinical features of abdominal tuberculosis (TB) have made its diagnosis difficult, which can lead to the poor outcome in patients who are not able to receive early treatment. Hence, the aim of our study was to determine the clinical profile of abdominal TB in the patients of Nepal.
\end{abstract}

Methods: This is a prospective observational study in which 103 patients with abdominal TB were analyzed for clinical profiles from May 2010 to April 2015. All diagnosed patients received anti-tubercular treatment (ATT) and were followed up at 1 and 6 months of ATT.

Results: Among 103 patients of abdominal TB [males 48 (46.6\%), females 55 (53.4\%); mean age 33.1 years ( \pm 12.9$)$ ], $47.6 \%$ had histopathological examination (HPE) confirmation, $27.2 \%$ had high ascitic adenosine deaminase (ADA) value and another $25.2 \%$ had suggestive imaging findings. The common symptoms were abdominal pain (84.5\%), weight loss (75.7\%), anorexia (63.1\%), chronic diarrhea (56.3\%) and fever (52.4\%). The mean weight was $<50 \mathrm{Kg}$, hemoglobin $<11 \mathrm{gm} / \mathrm{dl}$ and Erythrocyte Sedimentation Rate $>40 \mathrm{~mm} /$ first hour. The sites involved were ileo-cecal (35.9\%), peritoneal $(27.2 \%)$, ileal $(15.5 \%)$, colonic (15.5\%), lymph nodal (3.9\%) and gastroduodenal (1.9\%). The sensitivity of HPE for diagnosis of abdominal TB was $47.6 \%$ (95\% confidence interval $37.6 \%$ to $57.6 \%)$. All patients of abdominal TB had a good clinical response after ATT.

Conclusion: The common symptoms of abdominal TB were abdominal pain, weight loss, anorexia, chronic diarrhea and fever. Since the diagnosis of abdominal TB by HPE may not always be positive, other parameters such as ascitic ADA value, imaging findings and associated supportive clinical features have to be considered, and a therapeutic trial of ATT may be indicated so that all patients of abdominal TB can be treated early in the course of disease.

\section{INTRODUCTION}

Apart from the commonly occurring pulmonary tuberculosis (TB), the extra-pulmonary tuberculosis (EPTB) is also becoming a common cause of morbidity and mortality in a developing country like Nepal. The EPTB involves $11-16 \%$ of all patients of tuberculosis out of which 3 to $4 \%$ belong to abdominal TB. ${ }^{1}$ Primary gastrointestinal TB can occur as a result of ingestion of milk or food infected with Mycobacterium bovis, but it is rare nowadays. ${ }^{2}$ Infection with Mycobacterium tuberculosis causing abdominal TB can occur usually by swallowing of the infected sputum in active pulmonary $T B$, by hematogenous dissemination from a focus of active pulmonary TB or miliary $T B$, by lymphatic spread from infected mesenteric lymph nodes

\footnotetext{
* Corresponding author Umid Kumar Shrestha, MD, PhD Department of Medicine

Manipal College of Medical Sciences, Pokhara, Nepal Email: umidshrestha@gmail.com
} 


\section{| Original Article}

and by direct spreading from infected adjacent organs. ${ }^{3}$ The sites of Involvement in abdominal TB include gastrointestinal tract, peritoneum, lymph nodes and solid organs such as liver, spleen and pancreas. ${ }^{3}$

About $70-78 \%$ of abdominal TB is caused by gastrointestinal $\mathrm{TB}$, with ileocecal area being the most commonly involved site. ${ }^{4}$ The characteristic lesions produced in intestinal TB include ulcerative, hypertrophic, stricturous or constrictive and a combination of these forms such as ulcero-constrictive or ulcero-hypertrophic. ${ }^{2}$ Strictures are usually formed due to the cicatrical healing of ulcerative intestinal lesions. Peritoneal involvement occurs in $4-10 \%$ of EPTB and is caused by direct spread of TB from ruptured lymph nodes and intra-abdominal organs or hematogenous seeding. ${ }^{4}$ Peritoneal involvement may occur in the form of ascites or peritoneal adhesions; the mesenteric or retro-peritoneal lymph nodes are the main nodes involved in abdominal TB. Tubercular Infection often results in granuloma formation, caseation, mucosal ulceration, fibrosis, and scarring. ${ }^{4-7}$

Abdominal TB is a great mimic because of its varied clinical features and has been considered in a differential diagnosis of pyrexia of unknown origin, ${ }^{8}$ unexplained weight loss, ${ }^{9}$ and unexplained and chronic abdominal symptoms, ${ }^{10}$ hepatosplenomegaly, ${ }^{11}$ Crohn's disease, ${ }^{12}$ or gastrointestinal malignancy. ${ }^{13}$ The nonspecific clinical features have made the diagnosis of abdominal TB difficult. High index of suspicion is required to make a diagnosis of abdominal TB; otherwise, delayed diagnosis or misdiagnosis is likely to happen, which can lead to the poor outcome in patients who are not able to receive early treatment. There has been a few studies about the abdominal TB done in Nepal till date. ${ }^{14,15}$ Hence, the aim of our study is to determine the clinical profile of abdominal TB in the patients of Nepal.

\section{METHODS:}

This is a prospective observational study in which a total of 126 patients, presenting with clinical features suggestive of abdominal TB at Bir Hospital, National Academy of Medical Sciences, Kathmandu and Manipal Teaching Hospital, Pokhara, Nepal during a period of 5 years from May 2010 to April 2015, were enrolled. All patients underwent endoscopy (colonoscopy and or upper gastrointestinal endoscopy) and the sample of biopsy of the suspected lesion was received for histopathological examination (HPE). Among the patients with non-conclusive HPE report, but with strong clinical suspicion for the abdominal TB, other parameters, such as high ADA in ascitic fluid and suggestive imaging studies (barium studies, ultrasound and computed tomography), were utilized to diagnose abdominal TB. All patients received anti-tubercular treatment (ATT) for the first two months with Rifampicin, Isoniazid, Pyrazinamide and Ethambutol and the next four months with Rifampicin and Isoniazid. ${ }^{16}$ The patients were followed up after 1 month and 6 months to assess for the response.

Among a group of patients, whom HPE was not conclusive and ascitic ADA was not high, but a therapeutic trial of antitubercular treatment (ATT) was given, 23 patients did not do better with ATT on follow up of 1 month and was excluded from the study. Finally, 103 patients were labelled as having abdominal TB and were available for the analysis of the study. All of 103 patients were followed up after 6 months with a repeat colonoscopy and or UGI endoscopy to document the healing of the prior lesion.

The informed consent was taken from all patients and the study protocol was approved from the ethics committee of the participating centers.

The clinical features studied were pain abdomen, weight loss, anorexia, chronic diarrhea, fever, bloating, anemia, nausea, vomiting, bleeding per rectum, past history of TB, family history of TB, jaundice, lymphadenopathy, edema, clubbing, pulse, systolic blood pressure, diastolic blood pressure and weight.

The laboratory investigations included were sputum for Acid Fast Bacillus (AFB) staining, hemoglobin, white blood cell (WBC) total count and differential count, erythrocyte sedimentation rate (ESR) and other relevant parameters. The imaging study was done with chest X-ray, ultrasonogaphy and contrast enhanced computerized tomography scan of abdomen and pelvis in relevant patients. The location of disease was noted as ileal, ileo-cecal, colonic, ileocecal, colonic, gastroduodenal, peritoneal and lymph nodal. In the patients with ascites, the sample of ascitic fluid was assessed for Adenosine Deaminase (ADA), AFB staining and other parameters. The ascitic ADA level of $>33 \mathrm{U} / \mathrm{L}$ was considered as suggestive of tubercular ascites. ${ }^{17}$

During the endoscopic procedure, the morphological characteristics of the lesion were defined as ulceration, nodule, deformed ileo-cecal valve, mass and stricture.

The data were entered daily in a personal computer prospectively. The distribution of abdominal TB was recorded 
according to the gender, disease location and morphology of the lesion. The statistical analysis was done with SPSS 20.0 software (SPSS Inc., Chicago, IL, USA). A p value of $<0.05$ was considered statistically significant.

\section{RESULTS:}

Among 103 patients enrolled, only 49 (47.6\%) patients had histologically proven TB (Figure 1); 28 (27.2\%) patients had positive ADA value in the ascitic fluid and another 26 (25.2\%) patients, who did not show the histological confirmation of TB and who did not have ascites to check for ADA, had a suggestive radiological findings with a good clinical response, documented by a healing of intestinal lesion on a follow up endoscopy, after a therapeutic trial of ATT. The distribution of patients according to different diagnostic methods is shown in Table 1. Our study showed that the sensitivity of HPE confirmation for a diagnosis of abdominal TB was $47.57 \%$ (95\% Cl $37.64 \%$ to $57.65 \%$ ).

However, all of 103 patients were considered as having abdominal TB; among them, males and females were 48 (46.6\%) and 55 (53.4\%), respectively and mean age was 33.1 years ( \pm 12.9 ; range $14-72$ years). The distribution of patients according to the age group is shown in Table 2.

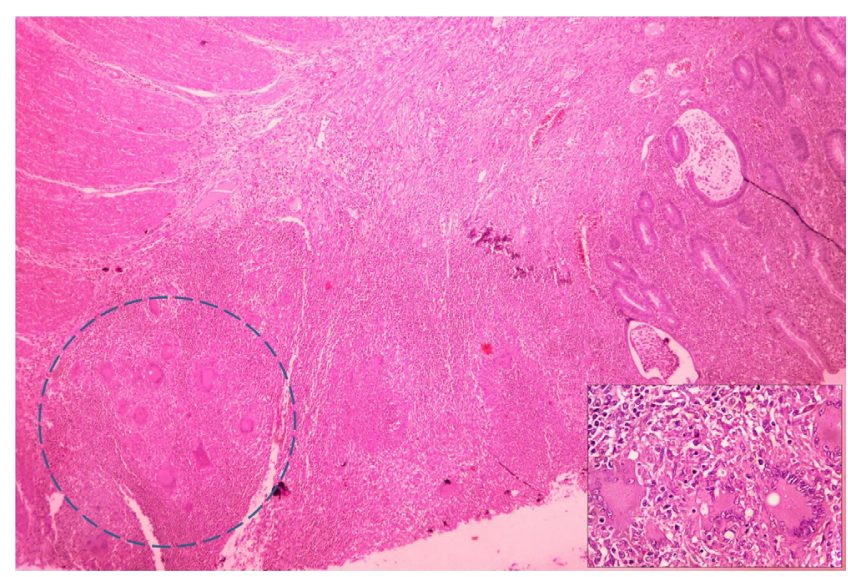

Figure 1: Microphotograph showing intestinal tuberculosis. Mucosa is on right side, marked dotted circle indicates epithelioid granuloma in the intestinal wall, H\&E, 50x ; Inset showing epithelioid granuloma and multinucleated Langhans giant cells, $H \& E, 400 x$

Table 1. Distribution of patients according to different diagnostic methods

\begin{tabular}{|l|c|c|l|}
\hline Diagnostic methods & $\begin{array}{l}\text { Male } \\
n=48 \\
(46.6 \%)\end{array}$ & $\begin{array}{l}\text { Female } \\
n=55 \\
(53.4 \%)\end{array}$ & $\begin{array}{l}\text { Total } \\
N=103\end{array}$ \\
\hline HPE proven & 21 & 28 & $49(47.6 \%)$ \\
\hline High ascitic ADA & 13 & 15 & $28(27.2 \%)$ \\
\hline
\end{tabular}

\begin{tabular}{|l|c|c|c|}
\hline $\begin{array}{l}\text { Clinical suspicion with } \\
\text { suggested radiological } \\
\text { features }\end{array}$ & 14 & 12 & $26(25.2 \%)$ \\
\hline
\end{tabular}

Table 2. Distribution of the patients of abdominal TB according to the age group

\begin{tabular}{|c|c|c|c|}
\hline $\begin{array}{c}\text { Age group } \\
\text { (years) }\end{array}$ & $\begin{array}{c}\text { Male } \\
\mathrm{n}=48(46.6 \%)\end{array}$ & $\begin{array}{c}\text { Female } \\
\mathrm{n}=55(53.4 \%)\end{array}$ & $\begin{array}{c}\text { Total } \\
\mathrm{N}=103\end{array}$ \\
\hline$\leq 20$ & $6(42.9 \%)$ & $8(57.1 \%)$ & 14 \\
\hline $21-30$ & $17(45.9 \%)$ & $20(54.1 \%)$ & 37 \\
\hline $31-40$ & $17(56.7 \%)$ & $13(43.3 \%)$ & 30 \\
\hline $41-50$ & $3(33.3 \%)$ & $6(66.7 \%)$ & 9 \\
\hline $51-60$ & $3(33.3 \%)$ & $6(66.7 \%)$ & 9 \\
\hline$>61$ & $2(50 \%)$ & $2(50 \%)$ & 4 \\
\hline
\end{tabular}

The overall distribution of clinical profile of patients with abdominal TB is shown in Table 3. Among the overall symptoms, abdominal pain was the most common symptom present in $84.5 \%$ of cases, followed by weight loss $(75.7 \%)$, anorexia (63.1\%), chronic diarrhea (56.3\%) and fever (52.4\%). The difference of clinical features among males and females were not statistically significant. The mean value of pulse, blood pressure, weight, hemoglobin, WBC counts and ESR is shown in Table 4. The mean weight of the patients was less than $50 \mathrm{Kg}$, hemoglobin less than $11 \mathrm{gm} / \mathrm{dl}$ and ESR more than $40 \mathrm{~mm}$ per first hour; however the mean value of pulse, blood pressure and WBC was within a normal range.

Table 3. Distribution of clinical profile of patients with abdominal TB

\begin{tabular}{|l|c|c|c|c|}
\hline \multicolumn{1}{|c|}{ Clinical Features } & $\begin{array}{c}\text { Male } \\
n=48 \\
(46.6 \%)\end{array}$ & $\begin{array}{c}\text { Female } \\
n=55 \\
(53.4 \%)\end{array}$ & $\begin{array}{c}\text { Total } \\
N=103\end{array}$ & $P$ \\
\hline Pain abdomen & $41(85.4 \%)$ & $46(83.6 \%)$ & $87(84.5 \%)$ & 0.803 \\
\hline Weight loss & $36(75 \%)$ & $42(76.4 \%)$ & $78(75.7 \%)$ & 0.872 \\
\hline Anorexia & $31(64.6 \%)$ & $34(61.8 \%)$ & $65(63.1 \%)$ & 0.772 \\
\hline Chronic diarrhea & $23(47.9 \%)$ & $35(63.6 \%)$ & $58(56.3 \%)$ & 0.109 \\
\hline Fever & $26(54.2 \%)$ & $28(50.9 \%)$ & $54(52.4 \%)$ & 0.741 \\
\hline Bloating & $18(37.5 \%)$ & $17(30.9 \%)$ & $35(34.0 \%)$ & 0.481 \\
\hline Anemia & $12(25.0 \%)$ & $20(36.4 \%)$ & $32(31.1 \%)$ & 0.214 \\
\hline Nausea & $11(22.9 \%)$ & $14(25.5 \%)$ & $25(24.3 \%)$ & 0.764 \\
\hline Vomiting & $8(16.7 \%)$ & $10(18.2 \%)$ & $18(17.5 \%)$ & 0.840 \\
\hline Bleeding per rectum & $4(8.3 \%)$ & $10(18.2 \%)$ & $14(13.6 \%)$ & 0.146 \\
\hline Past History of TB & $3(6.9 \%)$ & $5(9.1 \%)$ & $8(7.8 \%)$ & 0.591 \\
\hline Family History of TB & $1(2.1 \%)$ & $5(9.1 \%)$ & $6(5.8 \%)$ & 0.130 \\
\hline Jaundice & $1(2.1 \%)$ & $1(1.8 \%)$ & $2(1.9 \%)$ & 0.923 \\
\hline Lymphadenopathy & $1(2.1 \%)$ & $3(5.5 \%)$ & $4(3.9 \%)$ & 0.377 \\
\hline Edema & $1(2.1 \%)$ & $3(5.5 \%)$ & $4(3.9 \%)$ & 0.377 \\
\hline Clubbing & $2(4.2 \%)$ & $2(3.6 \%)$ & $4(3.9 \%)$ & 0.889 \\
\hline
\end{tabular}




\begin{tabular}{|l|l|l|l|l|}
\hline Sputum for AFB & $1(2.1 \%)$ & $1(1.8 \%)$ & $2(1.9 \%)$ & 0.923 \\
\hline
\end{tabular}

Table 4. Mean value of pulse, blood pressure, weight, hemoglobin, WBC counts and ESR

\begin{tabular}{|l|l|l|l|}
\hline \multicolumn{1}{|c|}{$\begin{array}{c}\text { Male } \\
(46.6 \%)\end{array}$} & \multicolumn{1}{|c|}{$\begin{array}{c}\text { Female } \\
\mathrm{n}=55\end{array}$} & \multicolumn{1}{c|}{$\begin{array}{c}\text { Total } \\
\mathrm{N}=103\end{array}$} \\
\hline $\begin{array}{l}\text { Pulse, mean (beats } \\
\text { per minute) }\end{array}$ & 87.3 (SD 11.5) & 84.4 (SD 10.4) & 85.7 (SD 11.0) \\
\hline SBP, mean (mm Hg) & 104.4 (SD 8.9) & 103.9 (SD 10.1) & 104.1 (SD 9.6) \\
\hline DBP, mean (mm Hg) & 70.6 (SD 6.1) & 70.9 (SD 6.9) & 70.8 (SD 6.6) \\
\hline Weight, mean (Kg) & 49.2 (SD 7.0) & 45.8 (SD 7.9) & 47.4 (SD 7.7) \\
\hline $\begin{array}{l}\text { Hemoglobin, mean } \\
\text { (g/dl) }\end{array}$ & 11.1 (SD 2.2) & 10.5 (SD 1.9) & 10.8 (SD 2.0) \\
\hline $\begin{array}{l}\text { WBC total count, } \\
\text { mean (per cu mm) }\end{array}$ & 9786.0 & 9356.9 & 9556.9 \\
\hline $\begin{array}{l}\text { Neutrophil, mean (per } \\
\text { cu mm) }\end{array}$ & 64.8 (SD 16.6) & 64.0 (SD 14.9) & 64.4 (SD 15.7) \\
\hline $\begin{array}{l}\text { Lymphocyte, mean } \\
\text { (per cu mm) }\end{array}$ & 32.7 (SD 16.6) & 32.8 (SD 15.8) & 32.8 (SD 16.1) \\
\hline $\begin{array}{l}\text { Eosinophil, mean (per } \\
\text { cu mm) }\end{array}$ & 1.1 (SD 1.2) & 1.1 (SD 1.2) & 1.1 (SD 1.2) \\
\hline $\begin{array}{l}\text { Monocyte, mean (per } \\
\text { cu mm) }\end{array}$ & 0.9 (SD 1.4) & 0.8 (SD 1.5) & 0.9 (SD 1.4) \\
\hline $\begin{array}{l}\text { ESR, mean (per first } \\
\text { hour) }\end{array}$ & 42.2 (SD 19.3) & 41.3 (SD 17.8) & 41.7 (SD 18.4) \\
\hline
\end{tabular}

SD: Standard Deviation; BP: Systolic Blood Pressure; DBP: Diastolic Blood Pressure

WBC: White Blood Cell; ESR: Erythrocyte Sedimentation Rate

The distribution of the location of disease in the patients of abdominal TB is shown in Table 5. The most common site of involvement in abdominal TB was ileo-cecal (35.9\%), followed by peritoneal (27.2\%), ileal (15.5\%) and colonic (15.5\%), lymph nodal (3.9\%) and gastroduodenal (1.9\%).

Table 5. Distribution of the location of disease in the patients with abdominal TB

\begin{tabular}{|l|c|c|c|}
\hline $\begin{array}{c}\text { Location of } \\
\text { Disease }\end{array}$ & $\begin{array}{c}\text { Male } \\
n=48(46.6 \%)\end{array}$ & $\begin{array}{c}\text { Female } \\
n=55(53.4 \%)\end{array}$ & $\begin{array}{c}\text { Total } \\
N=103\end{array}$ \\
\hline Ileal & $5(10.4 \%)$ & $11(20.0 \%)$ & $16(15.5 \%)$ \\
\hline Ileo-cecal & $15(31.2 \%)$ & $22(40.0 \%)$ & $37(35.9 \%)$ \\
\hline Colonic & $8(16.7 \%)$ & $8(14.5 \%)$ & $16(15.5 \%)$ \\
\hline Gastroduodenal & $0(0 \%)$ & $2(3.6 \%)$ & $2(1.9 \%)$ \\
\hline Peritoneal & $17(35.4 \%)$ & $11(20.0 \%)$ & $28(27.2 \%)$ \\
\hline Lymph nodal & $3(6.2 \%)$ & $1(1.8 \%)$ & $4(3.9 \%)$ \\
\hline
\end{tabular}

The endoscopic morphological characteristics of the intestinal tubercular lesion were ulcerative, nodular, stricture, mass, or combination of ulcerative-nodular lesion with or without stricture, or deformed ileo-cecal valve, which got healed completely after a course of ATT. (Figure 2 and 3).

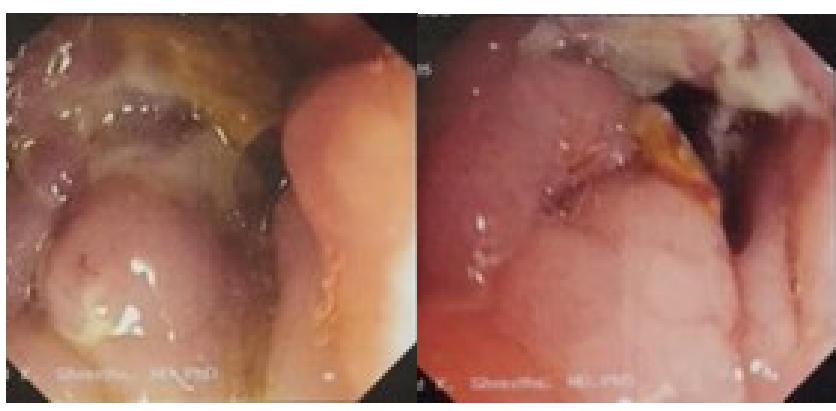

Figure 2: Colonoscopic picture showing multiple, irregular, nodular, ulcerated lesions, with a luminal narrowing in the descending colon.

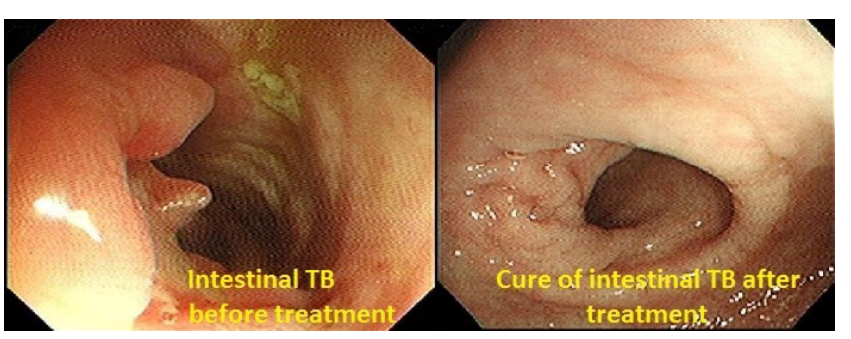

Figure 3: Colonoscopic picture showing irregular, ulcerative, thickened, multiple nodular lesions in the ileocecal valve, which was healed completely after a course of ATT.

\section{DISCUSSION}

Our study showed that the common symptoms of abdominal TB were abdominal pain, weight loss, anorexia, chronic diarrhea and fever, which were comparable to the other studies done previously and is shown in Table 6.

Table 6. Comparison of symptoms of abdominal TB in our studies with other different studies

\begin{tabular}{|l|c|c|c|c|}
\hline \multicolumn{1}{|c|}{ Symptoms } & $\begin{array}{c}\text { Current } \\
\text { study }\end{array}$ & $\begin{array}{c}\text { Mukewar } \\
\text { et al }{ }^{12}\end{array}$ & $\begin{array}{c}\text { Makharia et } \\
\text { al }^{18}\end{array}$ & Khan et al $^{19}$ \\
\hline Abdominal pain & $84.5 \%$ & $80.6 \%$ & $90.5 \%$ & $93 \%$ \\
\hline Weight loss & $75.7 \%$ & $74.6 \%$ & $83 \%$ & $47 \%$ \\
\hline Anorexia & $63.1 \%$ & $62.7 \%$ & $69.8 \%$ & $52 \%$ \\
\hline Fever & $52.4 \%$ & $40.3 \%$ & $41.5 \%$ & $64 \%$ \\
\hline Chronic diarrhea & $56.3 \%$ & $16.4 \%$ & $37.7 \%$ & $12 \%$ \\
\hline
\end{tabular}

In our study, the patients of abdominal TB presented with above symptoms had the mean weight less than $50 \mathrm{Kg}$, hemoglobin less than $11 \mathrm{gm} / \mathrm{dl}$ and ESR more than $40 \mathrm{~mm}$ per first hour.

Our study revealed that abdominal TB is a relatively common type of EPTB in Nepal with Intestinal TB being the commonest type, followed by peritoneal TB and mesenteric lymph nodal TB; among the intestinal TB, ileo-cecal region was the most 
common site to be affected, which was in conformity with the previous findings of the other studies..$^{3,20}$

The main basis for frequent involvement of the ileocaecal region is unknown, but it may be due to a variety of factors such as increased rate of absorption of fluid or electrolyte, abundance of lymphoid tissue in the form of Peyer's patches, physiological stasis, and minimal digestive activity at the ileocaecal region. ${ }^{20}$

Our patients of abdominal TB had the mean age of 33.1 years ( \pm 12.9 years), which is comparable to the findings from the other studies. $^{21-23}$

In our study, the gender distribution was almost equal, which was similar to the finding from Pakistan. ${ }^{20}$

Out of 103 patients of abdominal TB in our study, only $47.6 \%$ patients had histologically proven TB; remaining $27.2 \%$ patients were diagnosed by positive ascitic ADA value and $25.2 \%$ patients were by suggestive radiological findings with a good clinical response, after a therapeutic trial of ATT. Our study was comparable with the study done in Bangladesh, which showed that out of 25 patients of abdominal TB, $9(36 \%)$ had caseating granuloma in biopsy specimen, $1(4 \%)$ had positive AFB staining, 8 (32\%) had suggestive radiological findings, and 7 (28\%) had characteristic clinical features, that responded with therapeutic trial of ATT. ${ }^{24}$ In another study done in Bangladesh, the diagnosis of abdominal TB was confirmed microscopically in 5 (9.43\%) and histopathologically in 31(58.49\%); the remaining $17(32.07 \%)$ cases were diagnosed by a positive response to $\mathrm{ATT}^{25}$

One study done in India showed that out of 62 patients of abdominal TB, histopathology revealed collection of epithelioid cells only in 18 (29\%) and granuloma in 27 (43.5\%), and rest of the patients did better on therapeutic trial of ATT. ${ }^{26}$ This showed that it is difficult to diagnose all of the patients of abdominal TB, based only upon the histopathological criteria; the low yield on histopathology could be because of predominant submucosal involvement.

Our study showed that ulcerative lesions, nodules, stricture, mass or combination of ulcerative-nodular-lesion or ulcerativemass lesion with or without stricture, or deformed ileo-cecal valve were the macroscopic features of intestinal TB during endoscopy, which was in conformity with the published literature. ${ }^{18}$ The recommended treatment for abdominal TB is conventional anti-TB therapy for a minimum of 6 months. ${ }^{21} \mathrm{All}$ of our diagnosed patients of abdominal TB were successfully treated medically. Hence, prompt treatment after early diagnosis can improve the morbidity and mortality of the patients with abdominal TB.

Our study was not without limitations. Since the study was done in two different geographical locations (Kathmandu and Pokhara) of Nepal, there might be some bias related to the demographics of patient population in each medical center; the endoscopic provider was also different in these two medical centers; hence, the bias related to the endoscopic provider in interpreting the endoscopic morphological characteristics of the intestinal lesion might be present. As the study was done in the medicine department of these centers, data of some patients with abdominal TB admitted in surgery department might have been missed.

Conclusion: The common symptoms of abdominal TB were abdominal pain, weight loss, anorexia, chronic diarrhea and fever. The diagnosis of abdominal TB by HPE may not always be positive. Hence, other parameters such as ascitic ADA value, imaging findings and associated supportive clinical features have to be considered, and a therapeutic trial of ATT may be indicated so that all patients of abdominal TB can be treated early in the course of disease.

Conflict of interest: None declared 


\section{REFERENCES:}

1. Sharma SK, Mohan A. Extrapulmonary tuberculosis. Ind J Med Res 2004;124:316-53.

2. Chugh SN, Jain V. Abdominal Tuberculosis - Current Concepts in Diagnosis and Management. Medicine update 2007;17:600-8.

3. Debi U, Ravisankar V, Kaushal KP, Sinha SK, et al. Abdominal tuberculosis of the gastrointestinal tract: Revisited .World J Gastroenterol 2014;20:14831-40.

4. Sharma MP, Bhatia V. Abdominal tuberculosis. Ind J Med Res 2004;120:305-15.

5. Marshall JB. Tuberculosis of the gastrointestinal tract and peritoneum. Am J Gastroenterol 1993;88:989-99.

6. Bernhard JS, Bhatia G, Knauer CM. Gastrointestinal tuberculosis: an eighteen patient experience and review. J Clin Gastroenterol 2000;30:397-402.

7. Jakubowski A, Elwood RK, Enarson DA. Clinical features of abdominal tuberculosis. J Infect Dis 1988;158:68792.

8. Palmer KR, Patil DH, Basran S, et al. Abdominal tuberculosis in urban Britain: a common disease. Gut 1985;26:1296-305.

9. Underwood MJ, Thompson MM, Sayers RD, et al. Presentation of abdominal tuberculosis to general surgeons. Br J Surg 1992;79:1077-9.

10. Walia HS, Khafagy AR, al Sayer HM, et al. Unusual presentations of abdominal tuberculosis. Can J Surg 1994;37:300-6.

11. Essop AR, Posen JA, Hodkinson JH, et al. Tuberculous hepatitis: a clinical review of 96 cases. Q J Med 1984;212:465-77.

12. Makharia GK, Srivastava $S$, Das $P$, et al. Clinical, endoscopic, and histological differentiations between Crohn's disease and intestinal tuberculosis. Am J Gastroenterol. 2010;105:642-51.

13. Altintoprak F, Dikicier E, Cakmak G, et al. Intestinal Tuberculosis Mimicking Colon Carcinoma. Global Journal of Surgery, 2013, Vol. 1, No. 3, 15-18.

14. Kishore $\mathrm{P}$, Chandrsekhar T, Palaian S. Diagnosing
Abdominal Tuberculosis: A Retrospective Study From Nepal. The Internet Journal of Gastroenterology 2007;6:1-6.

15. Shrestha S, Pradhan GB, Bhoomi K, et al. Abdominal tuberculosis in Nepal Medical College Teaching Hospital, Kathmandu. SAARC Journal of Tuberculosis, Lung Diseases and HIV/AIDS 2008;5:40-3.

16. National Tuberculosis Centre, Nepal. National Tuberculosis Programme, A clinical manual for Nepal. $3^{\text {rd }}$ edition, 2009.

17. Dwivedi M, Misra SP, Misra V, et al. Value of adenosine Deaminase estimation in the diagnosis of tuberculous ascites. Am J Gastroenterol 1990;85:1123- 5.

18. Mukewar S, Mukewar S, Ravi R, et al. Colon Tuberculosis: Endoscopic Features and Prospective Endoscopic Follow-Up After Anti-Tuberculosis Treatment. Clin Transl Gastroenterol. 2012;3:e24.

19. Khan R, Abid S, Jafri W, et al Diagnostic dilemma of abdominal tuberculosis in non-HIV patients: an ongoing challenge for physicians. World J Gastroenterol 2006; 12:6371-5.

20. Saaiq M, Shah SA, Zubair M. Abdominal Tuberculosis: Epidemiologic profile and management experience of 233 cases. J Pak Med Assoc 2012;62:704-7.

21. Lazarus AA, Thilagar B. Abdominal tuberculosis. Dis Mon 2007;53:32-8.

22. Das $P$, Shukla HS. Clinical diagnosis of abdominal tuberculosis. Br J Surg 1976;63:941-6.

23. Kapoor VK, Sharma LK. Abdominal tuberculosis. Br J Surg 1988;75:2-3.

24. Sharma YR, Roy PK, Hasan M. Abdominal tuberculosis--a study of 25 cases. Kathmandu Univ Med J 2004;2:13741.

25. Miah AR, Sharma YR, Rahman MT, et al. Clinicopathological Profile of Patients with Abdominal Tuberculosis. J Nepal Health Res Counc 2011;9:169-75.

26. Singh V, Kumar P, Kamal J, et al. Clinicocolonoscopic profile of colonic tuberculosis. Am J Gastroenterol 1996; 91:565-8. 